2

3

4

5

6

\title{
Spherulite crystallization induces Fe-redox redistribution in silicic melt
}

Jonathan M. Castro ${ }^{1 *}$, Elizabeth Cottrell ${ }^{1}$, Hugh Tuffen $^{2}$, Amelia Logan ${ }^{1}$, and Katherine A. Kelley ${ }^{3}$

${ }^{1}$ Department of Mineral Sciences, Smithsonian Institution, $10^{\text {th }}$ and Constitution Ave. NW, Washington, DC 20560

${ }^{2}$ Department of Environmental Science, Lancaster University, LA1 4YQ, UK

${ }^{3}$ Graduate School of Oceanography, University of Rhode Island, Narragansett, RI 02882

"Corresponding author: email: castroj@ si.edu; phone: 202-633-1810; fax: 202-3572476

\section{Abstract}

Rhyolitic obsidians from Krafla volcano, Iceland, record the interaction between mobile hydrous species liberated during crystal growth and the reduction of ferric iron in the silicate melt. We performed synchrotron $\mu$-FTIR and $\mu$-XANES measurements along a transect extending from a spherulite into optically distinct colorless and brown glass zones. Measurements show that the colorless glass is enriched in $\mathrm{OH}$-groups and depleted in ferric iron, while the brown glass shows the opposite relationship. The color shift between brown and clear glass is sharp, suggesting that the colorless glass zone was produced by a redox front that originated from the spherulite margin and moved through surrounding melt during crystallization. We conclude that the most likely reducing agent is hydrogen, produced by magnetite crystallization within the spherulite. The Krafla flow dramatically captures redox disequilibrium on the micoscale and highlights the importance of hydrous fluid liberation and late stage crystallization to the redox signature of glassy lavas. 


\section{1. Introduction}

36 The chemical and physical processes in magma are influenced by the concentration and

37 reaction of hydrogen-bearing components in the silicate melt. It is well known that the

38 concentrations of molecular $\mathrm{H}_{2} \mathrm{O}$ and $\mathrm{OH}^{-}$groups, hereafter referred to collectively as

39 "water", dissolved in magma govern the positions of mineral liquidus curves and melt

40 viscosities; both rise dramatically, resulting in crystallization (e.g., Geschwind and

41 Rutherford, 1995) and melt stiffening (Hess and Dingwell, 1996), as magma degasses.

42 The relationship between water and the ratio of ferric to ferrous iron in silicate melts

43 remains an active area of research. In $\mathrm{H}_{2}$-buffered systems, the dissociation of water

44 (e.g., $\mathrm{H}_{2} \mathrm{O} \rightarrow \mathrm{H}_{2}+1 / 2 \mathrm{O}_{2}$, Mueller, 1971) controls oxygen fugacity $\left(f \mathrm{O}_{2}\right)$; thus $a \mathrm{H}_{2} \mathrm{O}$

45 controls $\mathrm{Fe}^{3+} / \mathrm{Fe}^{2+}$. The effect of water as a chemical component at fixed $\mathrm{P}, \mathrm{T}$, and $f \mathrm{O}_{2}$ is

46 more nuanced. The study of (Baker and Rutherford, 1996) suggested that the $\mathrm{Fe}^{3+} / \mathrm{Fe}^{2+}$

47 ratio increased with the addition of water; however, as discussed by Wilke et al. (2005)

48 and Gaillard et al. (2001), the study of Baker and Rutherford was not at constant oxygen

49 fugacity $\left(f \mathrm{O}_{2}\right)$. Experimental studies on rhyolite (Moore et al., 1995) and basalt

50 (Botcharnikov et al., 2005) indicate that water, as a chemical component in a melt held at

51 fixed T, $\mathrm{P}$, and oxygen fugacity $\left(f \mathrm{O}_{2}\right)$, has no effect on the $\mathrm{Fe}^{3+} / \mathrm{Fe}^{2+}$ ratio. By contrast,

52 other experimental studies indicate that as the bulk water content in increases so too does

53 the $\mathrm{Fe}^{3+} / \mathrm{Fe}^{2+}$ in the melt (Gaillard et al., 2001; Gaillard et al., 2003b). The relationship

54 between water and iron redox state in natural magmas is thus an important factor to

55 consider when reconstructing redox history of degassing magma (e.g., Mathez, 1984;

56 Burgisser and Scalliet, 2007) or deciphering the oxidation states of magma source regions 
57 (e.g., Carmichael, 1991).

58 Most natural magmas crystallize and vesiculate during their ascent towards and

59 emplacement at the Earth's surface. Because these phase transformations redistribute and

60 ultimately release volatile components from the system, they can drive oxidation-

61 reduction (redox) reactions that will alter the speciation of iron in the magma.

62 Crystallization of silicate minerals that preferentially incorporate ferrous iron in their

63 structures, such as olivine and pyroxene, result in a relatively oxidized melt residuum.

64 The manner by which crystallization of non-ferrous minerals such as quartz and feldspar

65 affects the residual melt redox state is currently unknown; however, because these phases

66 are anhydrous, their growth must redistribute water in the melt (Castro et al., 2008;

67 Watkins et al., 2009), thereby influencing the chemical environment of iron (Gaillard et

68 al., 2003c).

69 The release of $\mathrm{H}_{2}$ from magma, either through its continuous outward diffusion or

70 by liberation of $\mathrm{H}_{2}$ gas in bubbles is widely thought to oxidize lavas (e.g., Sato and

71 Wright, 1966; Sato, 1978; Mathez, 1984; Candela, 1986; Christie et al., 1886; Holloway,

72 2004). The diffusive transport of hydrogen out of the melt $(m)$ and into bubbles $(v)$

73 displaces the following equilibrium to the right: $2 \mathrm{FeO}_{(m)}+\mathrm{H}_{2} \mathrm{O}_{(m)}=\mathrm{H}_{2(v)}+\mathrm{Fe}_{2} \mathrm{O}_{3(m)}$.

74 Crystallization of magnetite may similarly alter the oxidation state of basaltic and silicic

75 systems by the "auto-oxidation" reaction as defined by Holloway (2004):

76

$$
3 \mathrm{Fe}^{2+} \mathrm{O}_{(m)}+\mathrm{H}_{2} \mathrm{O}_{(m)}=\mathrm{H}_{2 \text { (fluid) }}+\mathrm{Fe}^{2+} \mathrm{O} \cdot \mathrm{Fe}_{2}{ }^{3+} \mathrm{O}_{3} \text { (magnetite) }
$$

77 The net effect of this reaction on system redox will be determined by the degree to

78 which $\mathrm{H}_{2}$ gas exits the system. If the hydrogen escapes the magmatic system completely

79 (e.g. to bubbles or the atmosphere), the system is left relatively oxidized. If the hydrogen 
80 is retained within the system, however, it may generate relatively reducing fluids adjacent

81 to the zone of crystallization as proposed by Holloway (2004). Here we report adjacent

82 zones of oxidation and reduction in the Krafla flow on a scale of only hundreds of

83 microns.

84 In this paper, we describe fine-scale optical and chemical patterns in obsidian that

85 link spherulitic plagioclase, quartz, and magnetite crystallization to reduction of ferric

86 iron in the rhyolitic melt (Fig. 1). We show that reduced, colorless glass rims jacketing

87 spherulites could have been produced by the expulsion of molecular water from growing

88 spherulites, followed by crystallization of magnetite and concomitant production of

89 hydrogen. The result is a boundary layer of reduced melt that grows with time. Given

90 the considerable sizes (>1 m; Smith et al., 2001) and high volume proportions of

91 spherulites in many rhyolitic lavas and ignimbrites ( 90 vol.\%; Stevenson et al., 1994;

92 Tuffen and Castro, 2009; Tuffen et al., in Review) the interplay of crystallization and

93 micro-scale redistribution of oxidation states has important implications for the evolution

94 of spherulite-rich lavas.

95 2. Geological Background

96 Spherulites are radiating, often concentrically arranged crystalline aggregates set

97 in a glassy matrix (Fig. 1). They occur in obsidian domes, vitrophyric ash-flow tuffs

98 (e.g., Smith et al. 2001), large-volume rhyolite flows such as those at Yellowstone (e.g.,

99 Wright, 1915), and in shallow volcanic conduits (e.g., Stasiuk et al. 1996; Tuffen and

100 Castro, 2009). Spherulites nucleate and grow in response to large undercoolings (>

$101200 \mu \mathrm{C}$ ) rapidly imposed on the magma by its degassing and quenching (e.g., Swanson et

102 al., 1989). As dictated by the thermal profile of a magma body (Manley, 1992; Tuffen et 
103 al., in Review), spherulitic obsidian develops in spatially restricted zones (e.g., Manley

104 and Fink 1987; Stevenson et al. 1994), comprising a transitional facies that separates the

105 rapidly quenched, outermost vitrophyric rhyolite from a devitrified microcrystalline core.

106 Anomalously high volatile contents exist within and just above the spherulitic

107 zones in lava domes (e.g., Westrich et al. 1988). Castro et al. (2008) have recently shown

108 that the $\mathrm{OH}^{-}$concentrations in glass around spherulites are elevated above the background

109 level. They interpreted these $\mathrm{OH}^{-}$concentration gradients to reflect the combined

110 advection and diffusion of $\mathrm{H}_{2} \mathrm{O}$ away from the growing spherulites and numerically

111 modeled these processes in order to estimate crystallization timescales. While their work

112 confirms that spherulite crystallization drives volatile enrichment in silicic glass, it

113 neither identifies the specific form of hydrous species ejected from the growing

114 spherulite, nor constrains why an iron redox shift, manifested as a sharp color difference

115 in the obsidian matrix (Fig. 1), is superimposed on the $\mathrm{OH}^{-}$concentration gradient in the

116 glass. In this paper, we use microscopic chemical and textural evidence collected from

117 the same sample studied by Castro et al. (2008) to demonstrate that regions of elevated

$118 \mathrm{OH}^{-}$are linked to zones of iron reduction in the glass surrounding spherulites. This in

119 turn suggests that spherulite growth may cause changes in the Fe-valence state in rhyolite

120 melt.

121 3. Analytical and experimental techniques

122 All analyses were made on a decimeter-sized obsidian sample collected from the

123 Hrafntinnuhryggur ridge system on Krafla volcano, Iceland (Tuffen and Castro, 2009).

124 Spherulite mineralogy was determined by 1) microscopic observation, 2) sample

125 magnetism to identify Fe-oxides as magnetite, and 3) compositional data from energy 
126 dispersive spectra (EDS) collected on a FEI NOVA nanoSEM600 FEG Variable Pressure

127 Scanning Electron Microscope at the Smithsonian Institution National Museum of

128 Natural History, operated at 7-12 KeV, $5 \mathrm{~mm}$ working distance and beam current ranging

129 from $0.5-1 \mathrm{nA}$.

130 Major element glass compositions were analyzed using a JEOL JXA-8900R

131 electron microprobe (EPMA) running software with ZAF corrections at the Smithsonian

132 National Museum of Natural History. Analyses were performed with an acceleration

133 voltage of $15 \mathrm{keV}$, a $10 \mu \mathrm{m}$ beam, and a $10 \mathrm{nA}$ beam current. Standardization was

134 performed on the following natural mineral standards: Quartz ( $\mathrm{Si}$ ), Anorthite (Ca),

135 Bytownite (Al), Microcline (K), Albite (Na), Hornblende (Fe, Mg). A natural rhyolitic

136 glass (VG568, Obsidian Cliffs, Yellowstone, USA) of known major element composition

137 was periodically analyzed to check for instrument drift.

138 Determination of ferrous iron content was via wet chemical analysis of a

139 powdered (grain size $180 \mu \mathrm{m}$ ) obsidian aliquot chipped from the same mass of sample

140 on which all other measurements and observations were made. We attempted to separate

141 out spherulite fragments from the glass powder. However, some glass-encrusted

142 spherulites may have been over looked. Furthermore, it was not possible to separate the

143 thin, clear glass halos from the pervasive brown glass. Thus, these measurements provide

144 an average $\mathrm{FeO}$ concentration for the bulk brown glass with very minor dilution by the

145 clear glass fraction. A total of nine (9) analyses were performed following the technique

146 of Peck (1964) with some minor modifications in order to minimize oxidation during

147 sample digestion. Digestion began in $8 \mathrm{ml}$ of fluoroboric acid (HBF4) for 30 minutes in

148 the ultrasonic bath. We then added $5 \mathrm{ml} \mathrm{HF}$ and $2 \mathrm{ml}$ extra of HBF4 to the solution and 
149 completed the digestion under heat for approximately 10 minutes. Three ferrous iron

150 determinations were also made on the U.S.G.S. Glass Mountain Rhyolite standard RGM-

151 , which yielded a mean value of 1.19 wt. $\% \mathrm{FeO}+/-0.03(1 \sigma)$. The nominal value for

152 RGM-1 is 1.18 wt. \% FeO.

$153 \quad \mathrm{H}_{2} \mathrm{O}$ concentrations were determined by synchrotron-FTIR at the Advanced Light

154 Source, Lawrence Berkeley National Laboratory. Measurements were made along

155 traverses oriented perpendicular to the spherulite-glass boundaries on a Thermo Nicolet

156 Magna 760 FTIR spectrometer interfaced with a NicPlan IR microscope (at beamline

157 1.4.3). The IR beam has a diffraction-limited diameter of about $3 \mu \mathrm{m}$. The uncertainty in

158 spot position is $\pm 2 \mu \mathrm{m}$. Transmittance spectra were obtained over the mid-IR $(1,400$ -

$1594,000 \mathrm{~cm}-1)$ to the near-IR $\left(3,700-6,500 \mathrm{~cm}^{-1}\right)$ regions with MCT detectors, $\mathrm{KBr}$ beam-

160 splitters, and the synchotron light source. 128 scans were used to obtain each spectrum

161 and these spectra were corrected by subtracting a background spectrum collected every

162 hour. We determined $\mathrm{OH}^{-}$concentrations from the intensity of the broad $3,570 \mathrm{~cm}^{-1}$

163 absorption band, utilizing an absorption coefficient of $100 \mathrm{~L} \mathrm{~mol} \cdot \mathrm{cm}^{-1}$ (Newman et al.

164 1986). We estimate the analytical uncertainty of $\mathrm{OH}$ - concentration to be $\pm 10 \%$ of the

165 measured value.

166 The oxidation state of Fe in the glass was determined at the microscale using Fe

167 K-edge X-ray Absorption Near Edge Structure ( $\mu$-XANES) spectroscopy. The area-

168 weighted average energy of the two pre-edge peaks, or centroid, shifts to higher energy as

169 the ratio of ferric to ferrous iron increases, allowing quantification of $\mathrm{Fe}^{3+} / \Sigma \mathrm{Fe}$ in silicate

170 glasses (e.g. Berry et al., 2003, Wilke et al., 2005, Cottrell et al., in press). Commensurate

171 with this, the intensity of the peak corresponding to $\mathrm{Fe}^{3+}$ (at higher energy) grows 
172 proportionately larger relative to the intensity of the peak corresponding to $\mathrm{Fe}^{2+}$ (at lower

173 energy); thus the ratio of peak intensities can also be used to quantify oxidation state

174 (Wilke et al., 2005, Cottrell et al., in press).

175 Spectra were collected in fluorescence mode using a 9 element Ge array detector 176 and a silicon channel-cut (311) monochromator at station X26A (bending magnet) at the

177 National Synchrotron Light Source (NSLS), Brookhaven National Lab. The spot size on 178 the sample was $9 \times 5 \mu \mathrm{m}$. Spectra were recorded from $7020-7220 \mathrm{eV}$ with a $0.1 \mathrm{eV}$ step

179 over the pre-edge from $7106-7118 \mathrm{eV}$ at $5 \mathrm{~s}$ dwell. The pre-edge was deconvolved from

180 the background absorption edge by simultaneously fitting the background with a damped

181 harmonic oscillator function plus a line constrained to have a positive slope and the pre-

182 edge features with two Gaussian peaks. The oxidation state of the glass was quantified

183 using the empirical calibrations in Cottrell et al. (in press) based on pre-edge peak

184 intensity ratios measured on a series of 16 basalt reference glasses with $\mathrm{Fe}^{3+} / \Sigma \mathrm{Fe}$ ratios

185 (0.088-0.601) independently determined by Mössbauer spectroscopy and 7 rhyolitic

186 glasses with $\mathrm{Fe}^{3+} / \Sigma \mathrm{Fe}$ ratios (0.238-0.806) independently determined by wet chemistry

187 (Moore et al., 1996).

188 We performed a heating experiment on Krafla obsidian in order to induce

189 spherulite crystallization and determine if optical and chemical changes in neighboring

190 melt could result from this crystallization. General experimental details are given here,

191 while more detailed experimental methods are given in the appendix. We first heated a 2

$192 \mathrm{~cm}$-edge-length obsidian cube in a split-chamber tube furnace to $770^{\circ} \mathrm{C}$ at a rate of $65^{\circ} \mathrm{C}$

$193 \min ^{-1}$. The sample was held at $770^{\circ} \mathrm{C}$ for 90 minutes. After this period of time, the cube

194 was removed from the furnace and blasted with cold compressed air, which cooled it to 
195 room temperature in about 3 minutes. We then extracted a thin $(\sim 225 \mu \mathrm{m})$, doubly

196 polished wafer from the center of the cube and examined the glass and spherulites near

197 the center of that wafer. We also measured a water concentration profile along a traverse

198 extending from one of the spherulites in the wafer center. We performed a similar

199 experiment at $870^{\circ} \mathrm{C}$, but the hydrous melt adjacent to the spherulites vesiculated

200 intensely, rendering comparisons between the experimentally heated and natural

201 unvesiculated samples difficult. Due to a lack of obsidian starting material, we could not

202 repeat the experiment at $770^{\circ} \mathrm{C}$.

203

204 4. Results

205 4.1 Analytical measurements

206 Fig.1a is a photomicrograph of a natural spherulitic obsidian wafer that is the 207 subject of the measurements discussed in the following paragraphs. The spherulites in 208 this sample are composed of plagioclase and quartz ( 95 vol.\%), and minor amounts of

209 clinopyroxene (2-3 vol.\%) and magnetite (<0.8 vol.\%; Castro et al., 2008). All of the

210 spherulites are enclosed in haloes of colorless to light brown glass, which separate them

211 from the pervasive dark brown matrix glass. The transitions between brown and

212 colorless glass tend to be sharp around the larger spherulites (radii $>100 \mu \mathrm{m}$ ) whereas the

213 boundaries are more diffuse around the smaller spherulites.

214 Fig. $1 \mathrm{~b}$ shows a representative $\mathrm{OH}^{-}$concentration profile measured with

215 synchrotron-FTIR by Castro et al. (2008). The area under the profile is proportional to

216 the amount of $\mathrm{OH}^{-}$groups in the silicate glass surrounding the spherulite. Castro et al.

217 showed that the $\mathrm{OH}^{-}$concentration increases with the spherulite size, and typically 
218 matches the amount of water that would be ejected during complete crystallization of

219 anhydrous minerals from a melt volume equal to that of the spherulite. Differences

220 between the measured and predicted $\mathrm{OH}^{-}$contents show that some spherulites retained

221 water during their growth, consistent with the presence of glass and microvesicles (Castro

222 et al., 2008).

223 Table 1 shows representative major element glass compositions measured within

224 and across the differently colored glass regions. These data show that the composition of

225 glass in the colorless halo, the transitional zone, and the distal brown glass surrounding

226 the spherulite in Fig.1a are indistinguishable within analytical error. Most importantly,

227 there is no discernable change in the total iron content as the spherulite-glass boundary is

228 approached; i.e., glass color is not a function of the total iron content but rather the ratio

229 of ferric to ferrous iron. Fig. 2 is a graph showing the major element compositions of

230 glass along a line traverse emanating from the spherulite shown in Fig. 1a.

231 By analogy with glasses equilibrated experimentally under controlled $f \mathrm{O}_{2}$, the

232 color difference between the halo and distal glass in the natural sample was suspected to

233 reflect the proportions of ferric and ferrous iron, with the darker brown glass having more

234 ferric iron than the light-colored glass (Gaillard et al. 2002; Donald et al., 2006;

235 Moriizumi et al., 2008). This hypothesis was confirmed with $\mu$-XANES measurements.

236 Spectra were collected on the spherulite shown in figure 1a both within the clear glass

237 rim, approximately $20 \mu \mathrm{m}$ from the spherulite-glass border, and in the far-field brown

238 matrix glass where the $\mathrm{OH}$-concentration flattens out, about $330 \mu \mathrm{m}$ from the spherulite

239 edge. Figure 3 ab shows the raw pre-edge spectra, model components, and total model

240 fits to the spectra. The spectrum taken in the distal brown glass (spot 2) displays a 
241 proportionately larger $\mathrm{Fe}^{3+}$ peak, indicative of a greater contribution from ferric iron. This

242 can be seen even more clearly in figure $3 \mathrm{c}$ when the baseline subtracted spectra are

243 superimposed. Quantitatively, the centroid (area-weighted average of the two pre-edge

244 peaks) shifts to higher energy by $0.18 \mathrm{eV}$ moving from the clear rim to the distal brown

245 glass. Consistent with this, the ratio of pre-edge peak intensities (i.e. $\mathrm{I}\left(\mathrm{Fe}^{3+}\right) / \mathrm{I}\left(\mathrm{Fe}^{2+}\right)$

$\left.246 \mathrm{I}\left(\mathrm{Fe}^{3+}\right) /\left[\mathrm{I}\left(\mathrm{Fe}^{2+}\right)+\mathrm{I}\left(\mathrm{Fe}^{3+}\right)\right]\right)$ shift to reflect a greater contribution from ferric iron in the

247 distal brown glass than in the halo, consistent with a relative change in the ratio of

$248 \mathrm{Fe}^{3+} / \sum \mathrm{Fe}$ of 0.06 . The $\mu$ XANES results clearly indicate a difference in the relative $\mathrm{Fe}$

249 oxidation state of the two glass regions, with the clear glass halos demonstrably reduced

250 relative to the brown matrix glass. The absolute ferric iron content determined for the

251 distal brown glass $\left(\mathrm{Fe}^{3+} / \sum \mathrm{Fe}=0.23 \pm 0.04\right)$ compares favorably with, but is more reduced

252 than, the wet chemical determination of $\mathrm{Fe}^{3+} / \sum \mathrm{Fe}=0.29 \pm 0.02$, whereas $\mathrm{Fe}$ in the clear

253 brown glass is more reduced $\left(\mathrm{Fe}^{3+} / \sum \mathrm{Fe}=0.17 \pm 0.04\right)$.

254 Fig. 4 shows measurements of the widths of several colorless glass haloes versus

255 their corresponding spherulite radii. Estimated uncertainties in rim widths, stemming

256 from the diffuse nature of the glass color boundaries, are shown as vertical error bars.

257 The nonlinear regression to the data is a power-law function relating rim width to

258 spherulite radius. Also shown in Fig. 4 are the predicted reduction rim widths for each

259 spherulite based on calculations using empirical relationship of Gaillard et al. (2003a),

260 which relates reduction front position or width to hydrogen fugacity, temperature $\left(800^{\circ} \mathrm{C}\right)$

261 and time. These model calculations will be discussed further below.

2634.2 Experimental results 
265 Figs. 5 and 6. To aid comparisons with the natural state, we also include images of 266 unheated spherulite-rim combinations collected on the spherulite shown in Fig.1. The

267 transmitted-light photomicrographs were taken at the same illumination and focal depth, 268 and the imaged wafers were about the same thickness.

269 The salient features and changes in the heated sample are: 1) thin, $\sim 10 \mu \mathrm{m}$ wide 270 veneers of plagioclase (identified with EDS on an SEM) jacketed all spherulites in the

271 sample, 2) thin brown fringes composed of glass, plagioclase, and magnetite crystals

272 located just inboard of the plagioclase veneers, 3) the colorless glass rims brigtened, and

273 on their outer periphery, thin, light-brown glass zones developed that appear to have

274 propagated toward the spherulites, 4) circumferential cracks formed parallel to the

275 colorless-brown glass boundaries, in some cases directly on them, and 5) along many of

276 these cracks, small, $\sim 10-30 \mu \mathrm{m}$, "bubble-trains" grew, comprising groups of spherical

277 (Fig. 5c) to nearly completely flattened vesicles (Fig. 5d).

278 The most apparent changes that occurred during the heating experiment were

279 crystallization and brightening of the colorless haloes (Fig. 5a, b). That the

280 crystallization was "new" is indicated by the fact that none of the unheated spherulites

281 have a jacket of feldspar around them. The crystallization rate implied by the amount of

282 new plagioclase $\left(\sim 1.7 \times 10^{-9} \mathrm{~m} \mathrm{sec}^{-1}\right.$; ie., width of plagioclase veneer divided by the

283 experiment time) is similar to the average value $\left(\sim 1.9 \times 10^{-9} \mathrm{~m} \mathrm{sec}^{-1}\right)$ determined by Castro

284 et al. (2008) from their diffusion models at $800^{\circ} \mathrm{C}$.

285 The circumferential fractures and small vesicle trains resulted from processes 286 occurring, respectively, below and above the rheological glass transition $\left(T_{\mathrm{g}}\right)$. At the 
287 given heating rate, the sample reached $T_{g}\left(\sim 700^{\circ} \mathrm{C}\right.$; Castro et al., 2008) in $\sim 10$ minutes.

288 During this short time the glass may have fractured due to its greater thermal expansion

289 compared to the mineral phases in the spherulite. If this were the case, then fractures

290 formed in tension as the expanding glass pulled away from the spherulite. Once the

291 fractures formed, and the glass passed through $T_{g}$, bubble nucleation occurred

292 preferentially along the fractures, which channeled volatile components to the growing

293 bubbles. The cracks apparently served as conduits for degassing of the volatile-enriched

294 boundary layers. An FTIR profile (Fig. 6) measured across one of these fractures

295 indicates that the dissolved $\mathrm{OH}^{-}$content decreases in the vicinity of a fracture, suggesting

296 degassing into that fracture.

298 5. Mechanism of Fe-reduction during crystallization

299 It is clear from the geometry of the colorless glass haloes, specifically their

300 proportional increase in width with spherulite size (Fig. 4), and their mimicking of the

301 spherulite shapes, that the colorless glass rims resulted from the growth of the spherulites.

302 The $\mu$-XANES spectra indicate that some ( $\sim 5-7 \%$ absolute or $26 \%$ relative) of the ferric

303 iron in the glass adjacent to the spherulites has been reduced to ferrous iron (Fig. 3). In

304 this section we address how these redox changes could have occurred in light of the

305 analytical and experimental evidence.

306 We first consider the possibility that the heterogeneous ferric-ferrous iron

307 distribution in the glass is related to the cooling history. Metrich et al. (2006) showed

308 that the ferric-ferrous ratio in peralkaline rhyolitic glass inclusions appeared to increase

309 upon slow cooling over several hundred ${ }^{\circ} \mathrm{C}$ in high temperature $\mu$-XANES experiments. 
310 They attributed the apparent oxidation in XANES spectra upon cooling to a change in the

311 coordination environment of iron; high temperature favors tetrahedrally coordinated

312 ferrous iron while lower temperatures stabilize octahedrally coordinated ferric iron.

313 Metrich et al conclude that the XANES spectra of slowly cooled samples will appear

314 more oxidized due to this coordination shift. To account for the reduced halos in the

315 spherulitic obsidian, the reduced halos would have had to cool much more rapidly than

316 the more oxidized distal brown glass, which is physically unlikely because latent heat

317 liberated from the growing spherulites would have slowed cooling of the melt adjacent to

318 the spherulite (Tuffen et al., submitted). Moreover, the color change in the glass supports

319 a real difference in the oxidation state of iron, not a coordination change. For these

320 reasons, this mechanism was probably not important for the formation of the colorless

321 rims.

322 We next consider the possibility that the reduced-Fe signature in the rims arose

323 from the late-stage crystallization of magnetite. The distribution of magnetite within

324 spherulites, mainly as radial aggregates sandwiched between larger domains of

325 plagioclase and quartz (Fig.1), suggests that magnetite grains formed in the latest stage of

326 crystallization, from an interstitial melt that would have been enriched in water, further

327 stabilizing magnetite (Sisson and Grove, 1993). Magnetite crystallization could act to

328 reduce the melt adjacent to the spherulite via two potential mechanisms. First, hydrogen

329 produced by magnetite crystallization in the presence of water (i.e., "auto oxidation,"

330 reaction 1) would necessarily diffuse out of the spherulite, and would have subsequently

331 reduced ferric iron in the neighboring melt. Second, magnetite crystallization alone will

332 reduce iron in the glass residuum by virtue of its higher ferric/ferrous ratio (just as olivine 
333 crystallization would raise the ferric/ferrous ratio). We show below that either

334 mechanism, or both in concert, could have generated the reduced halos.

335 "Auto-oxidation" as described by Holloway (2004) may proceed in hydrous

336 silicates when magnetite with a higher ferric/ferrous ratio than the melt from which it is

337 crystallizing becomes stable. Pure end-member magnetite has a $\mathrm{Fe}^{3+} / \sum \mathrm{Fe}$ of about 0.67 ,

338 compared to the value of $0.22-0.29$ in the brown glass; therefore magnetite precipitation

339 could have resulted in "auto oxidation" in this hydrous lava from Krafla. In this scenario,

340 magnetite precipitation proceeds through the consumption of water, generating one mole

341 of $\mathrm{H}_{2}$ for every mole of magnetite crystallized (reaction 1). If $\mathrm{H}_{2}$ leaves the system

342 completely through degassing along fractures, the remaining material is left relatively

343 oxidized. As $\mathrm{H}_{2}$ diffuses through a melt, however, it necessarily results in a reduction

344 front. We believe that these spherulites capture this disequilibrium state.

345 Simple mass balance arguments confirm the plausibility of this scenario. The

346 modal proportion of magnetite in the spherulites, determined by BSE image analysis on

34710 different spherulites, is about 0.3 vol. $\%( \pm 0.12)$. The amount of $\mathrm{Fe}^{3+}$ now residing in

348 the magnetite grains within the large spherulite pictured in Fig. 1a is about $0.003 \mathrm{mg} \mathrm{Fe}^{3+}$

$349\left(5.38 \times 10^{-08}\right.$ moles of $\left.\mathrm{Fe} 3+\right)$, and because these magnetite grains contain some Ti (Castro

350 et al., 2008), this estimate of $\mathrm{Fe}^{3+}$ in magnetite is a maximum. If all of the $\mathrm{Fe}^{3+}$ residing

351 in the magnetite were created by oxidation of $\mathrm{Fe}^{2+}$ in the liquid, magnetite crystallization

352 would produce a maximum of $2.7 \times 10^{-8}$ moles of $\mathrm{H}_{2}$ via reaction (1). This hydrogen could,

353 in turn, reduce $5.38 \times 10^{-8}$ moles of ferric iron (i.e. $0.003 \mathrm{mg}$ ) in the adjacent melt (and

354 produce water) according to: 


$$
\mathrm{H}_{2(s)}+\mathrm{Fe}_{2}{ }^{3+} \mathrm{O}_{3(m / g)}=2 \mathrm{Fe}^{2+} \mathrm{O}_{(m / g)}+\mathrm{H}_{2} \mathrm{O}(m / g)(2)
$$

358 Subscripts above refer to: $(s)$-spherulite and $(\mathrm{m} / \mathrm{g})$-melt/glass. If all of the $\mathrm{H}_{2}$

359 were transferred to the $100 \mu \mathrm{m}$ halo jacketing the spherulite in Figure 1a, it would shift

360 the percentage of $\mathrm{Fe}^{3+}$ from $\sim 22 \%$ (measured via XANES) to $9 \%$. We observe $\mathrm{Fe}^{3+}$ in the

361 halo equal to $16 \%$ (table 1), indicating that "auto-oxidation" within the spherulite could

362 actually be responsible for iron reduction in the halo. This calculation is a maximum

363 because it assumes that $100 \%$ of the ferric iron in the magnetite had to be converted from

$364 \mathrm{FeO}$ (i.e. reaction 1). We observe, however, that the brown glass contains about $22 \%$

365 ferric iron. Assuming that reaction (1) proceeded at $78 \%$ efficiency (i.e. $22 \%$ of the ferric

366 iron incorporated into the magnetite was already ferric), we still find that the percentage

367 of $\mathrm{Fe}^{3+}$ would drop to $11 \%$. Within the error of the XANES measurements, the

368 uncertainty of the reaction efficiency and mass balance, and even taking into account that

369 the magnetite is Ti-bearing, this scenario remains plausible.

370 The auto-oxidation scenario is also corroborated by the high concentration of

371 water in the halos. We observe the number of moles of " $\mathrm{H}_{2}$-equivalent" currently residing

372 in the halo (i.e. one half the moles of $\mathrm{OH}^{-}$, calculated from the $\mathrm{OH}^{-}$concentration of

$3730.19 \%$ measured by FTIR) equal to $5 \times 10^{-8}$. This is $\sim 45 \%$ higher than the number of

374 moles of $\mathrm{H}_{2}$ expected from magnetite crystallization via reaction (1). We therefore

375 observe more "water" (hydroxyl and molecular) in the glass surrounding these spherulites

376 than produced by magnetite crystallization. This "excess" water is expected because

377 water is also rejected as an incompatible element in the growing spherulite (Castro et al., 378 2008). 
A second mass-balance argument can be made that magnetite precipitation alone

380 (i.e. not relying on the presence of water) could have caused the reduction halos.

381 Magnetite incorporates iron in a ratio of $2 \mathrm{Fe}^{3+}: 1 \mathrm{Fe}^{2+}$. Only $0.4 \%$ magnetite

382 crystallization (as a percent of the glass now occupied by the reduced halos) is required to

383 cause the ferric iron to decrease from $\sim 22$ to the observed value of $\sim 16 \%$. If we assume

384 that all the magnetite seen in the spherulites crystallized from the volume of glass now

385 occupied by the reduced halos, we observe $0.7 \%$ crystallization (which would reduce the

386 ferric iron to $11 \%$ ). If we assume that all of the magnetite seen in the sphereulites

387 crystallized from the volume of glass that now comprises the volume occupied by the

388 spherulites plus the reduced halos, we observe $0.3 \%$ crystallization (which would reduce

389 the ferric iron to $18 \%$ ). These two values therefore bracket the maximum and minimum

390 extents of magnetite crystallization, and either extreme provides a reasonable mechanism

391 by which the glass in the halos could have been reduced. Crystallization of $0.4 \%$

392 magnetite from the halo would simultaneously cause the total iron concentration (FeO) in

393 the halo to fall from 3.2 to $2.8 \%$. This is close to within the error of the microprobe

394 measurements. We have the added uncertainty of not knowing if the iron concentration

395 could have been increased in the halo volume due to its incompatibility in early-

396 crystallizing quartz and plagioclase. Nevertheless, no decrease or gradient in the iron

397 concentration is observed in the halos relative to the distal brown glass. This, combined

398 with the demonstrable presence of water in the system and the likelihood of the auto-

399 oxidation reaction proceeding, leads us to slightly favor the auto-oxidation scenario as a

400 means of generating the halos, but neither can be ruled out and in fact both could have

401 contributed. 
Gaillard et al. (2003a, c) simulated the process of hydrogen-flux iron reduction by

403 exposing natural Fe-bearing rhyolitic melt and glass cylinders to reducing atmospheres of

404 hydrogen and hydrogen-argon gas mixtures. Their experiments produced many of the

405 features we observe around the natural spherulites: 1) a sharp change in glass color

406 bounding a zone of reduced $\mathrm{Fe}^{3+} / \mathrm{Fe}_{\text {total }}$ in hydrous glass, 2) sigmoidal $\mathrm{OH}^{-}$concentration

407 profiles emanating from the sample edge and attributable to hydrogen incorporation in

408 the melt followed by diffusion of molecular water along the concentration gradient, and

4093 ) an offset between the reaction front position and the point of elevated $\mathrm{OH}^{-}$in the glass.

410 Gaillard et al. (2003a, c) proposed that because hydrogen is very reactive with

411 iron in the silicate melt, the reaction front progress in the melt is governed by the

412 solubility and diffusion of hydrogen in the melt. The effective diffusion rate of $\mathrm{H}_{2}$, in

413 turn, was limited by the $\mathrm{fH}_{2}$ of their experiments. Gaillard et al. observed that the rate of

414 progress of the reduction front ( $\mu \mathrm{m}$ 's/hour) was several orders of magnitude slower than

415 the expected hydrogen diffusivity ( $\mu \mathrm{m}$ 's/sec) in the melt.

416 Gaillard et al. (2003a) performed time series experiments in order to characterize

417 the rate of advancement of the reduction front with time. They observed a square-root-

418 of-time dependence of the front position and, based on linear relationships between the

419 square of the reduction front position and run duration, they extracted reduction rate

420 constants, $K=\mu^{2} / t$, where $\mu$ is the reaction front position, and $t$ is time, for their

421 experiments at $800^{\circ} \mathrm{C}$ and a range of hydrogen fugacities (0.02-50 bars). They proposed

422 that the reduction rate was limited by hydrogen incorporation, which in turn, is a function

423 of the fugacity-dependent $\mathrm{H}_{2}$ solubility and diffusivity in the melt.

424 It is possible that the spherulites behaved in a similar manner, that is, they acted 
425 as hydrogen point sources to the neighboring melt. Although the boundary conditions are

426 slightly different, e.g., the spherulites are an internal, as opposed to external hydrogen

427 source, the empirical kinetic data of Gaillard et al. (2003c) can be used to assess whether

428 the widths of the natural reduction rims are compatible with the timescales of spherulite

429 growth. In other words, we assume that the reduction front started moving at the onset of

430 spherulite growth and stopped when the growth ceased. By this simple scenario, the rim

431 widths depend on the growth timescale, and therefore the duration that the expelled

432 hydrogen had to react with the rhyolite melt according to the reaction rate constant $K$

433 (Gaillard et al. 2003a).

434 Castro et al. (2008) estimated average spherulite growth rates by modeling the

435 combined advection and diffusion of water away from the growing spherulites and fitting

436 model profiles to the natural $\mathrm{OH}^{-}$concentration profiles. Even though their model did not

437 account for hydrogen incorporation in the melt and its unknown effect on the kinetics of

$438 \mathrm{H}_{2} \mathrm{O}$ diffusion, their growth rates match those determined experimentally on

439 compositionally similar melts (e.g., Baker and Freda, 2001), and are probably accurate to

440 an order of magnitude. According to their results at $800^{\circ} \mathrm{C}$ the spherulites grew at an

441 average rate of $\sim 10^{-9} \mathrm{~m} / \mathrm{s}$ (Castro et al., 2008), which is similar to the rate determined in

442 our spherulite growth experiments at $770^{\circ} \mathrm{C}$ (appendix).

443 Results of rim-width calculations are shown in Fig. 4. Individual spherulite

444 growth timescales were determined by dividing the average growth rate $\left(800^{\circ} \mathrm{C}\right.$; Castro et

445 al., 2008) by their spherulite radii. Using the individual growth timescales $(t)$, we

446 calculated rim widths $(\mu)$ using the relation $\mu=(K \bullet t)^{1 / 2}$. The best match between the

447 calculated and natural rim widths was attained with the $K$ value derived from the lowest 
$448 \mathrm{H}_{2}$ fugacity $\left(f \mathrm{H}_{2}=0.02\right.$ bar) in the experiments of Gaillard et al. (2003a). We found a very

449 large mismatch at their next highest $f \mathrm{H}_{2}\left(\sim 0.25\right.$ bar $\left.\mathrm{H}_{2}\right)$ and attribute this to the nearly one

450 order of magnitude increase in $K$ at $f \mathrm{H}_{2}=0.25$ bar, which translates to comparatively rapid

451 rim growth relative to the spherulite growth timescales.

452 The agreement between the calculated and real Fe-reduction rim widths is good,

453 suggesting that the natural rims could have developed under conditions of relatively low

454 hydrogen fugacity ( $\sim 02$ bar according to Gaillard et al., 2003a). This match supports

455 our hypothesis that it is molecular hydrogen that extrudes from the growing spherulite,

456 thereby fluxing the ferric iron in the neighboring melt and causing the propagation of a

457 redox front.

458

459 6. Experimentally induced spherulite growth and Fe-reduction

460 The experimental results of Gaillard et al (2003a, c) show that hydrogen fluxing

461 of a silicate melt or glass will cause reduction of the ferric iron and the formation of a

462 sharp reduction front that progresses with the square root of time. The close agreement

463 between these experimental results and our natural observations suggests that the

464 colorless haloes formed as a result of ferric iron reduction during spherulite growth, with

465 hydrogen being a permissible reductant.

466

\section{7. Conclusion}

468 Our analysis indicates that the spherulitic growth of anhydrous phases can cause

469 significant changes in Fe-oxidation state in the neighboring melt or glass around the

470 growing crystals. Fe-redox reactions are driven by the liberation of hydrogen, and we 
471 propose that it is hydrogen produced as a product of magnetite crystallization. The result

472 is an Fe-reduction reaction that propagates through the glass or melt with time. That

473 spherulite crystallization can cause reduction of ferric iron in the silicate melt suggests

474 that this phenomenon could prevent oxidation of silicic lavas during their emplacement

475 despite extensive crystallization. For example, Carmichael (1991) indicates that

476 voluminous post-caldera rhyolite lavas at Yellowstone National Park, USA underwent

477 little to no change in redox state compared to earlier-erupted ash flows. Carmichael

478 (1991) used the apparent lack of oxidation of these lavas to support his hypothesis that

479 "silicic magmas have redox states that reflect their source regions rather than $\mathrm{H}_{2}$ loss."

480 He further explained that the low bulk $\mathrm{H}_{2} \mathrm{O}$ content of the post caldera lavas could have

481 suppressed the activity of the $\mathrm{H}_{2} \mathrm{O}$ as most of the water would be speciated as $\mathrm{OH}$ groups

482 (Stolper, 1982).

483 Spherulite crystallization is widespread in the interiors of the Yellowstone

484 rhyolites (Wright, 1915; Colony and Howard, 1934), with some flows containing well

485 over 50 vol.\% spherulites (e.g., in the Nez Pierce flow). We suggest that the lack of

486 variation in redox state may have been enabled by spherulite crystallization and local

487 hydrogen solute rejection, but retention of generated hydrogen within the flows. Thus

488 Carmichael's (1991) conclusion that "silicic magmas with small amounts of iron and

489 large amounts of water do not have their redox states reset" upon eruption may be a

490 consequence of the offsetting effects of crystallization and glass reduction at the

491 microscale.

492

493 Acknowledgements 
494 We thank M.C. Martin for assistance with the SFTIR measurements and T. Gooding with

495 sample preparation. Antonio Lanzirotti provided critical assistance at X26A, NSLS,

496 Brookhaven National Lab. We thank F. Gaillard and M. Rutherford for valuable

497 discussions. Finally, we appreciate the help of Landsvirkjun and the staff at Krafla power 498 station during our sampling campaign in Iceland.

$500 \quad$ References

501 Bacon, C.R., Adami, L.H., Lanphere, M.A., 1989. Direct evidence for the origin of low

$502{ }^{18}$ O silicic magmas: quenched samples of a magma chamber's partially-fused granitoid

503 walls, Crater Lake, Oregon. Earth and Planetary Science Letters 96, 199-208.

504 Bajt, S., Sutton, S. R., Delaney, J. S., 1994. X-Ray Microprobe Analysis of Iron

505 Oxidation-States in Silicates and Oxides Using X-Ray-Absorption near-Edge Structure

506 (Xanes). Geochimica Et Cosmochimica Acta 58, 5209-5214.

507 Baker, D.R., Freda, C., 2001. Eutectic crystallization in the undercooled Orthoclase-

508 Quartz- $\mathrm{H}_{2} \mathrm{O}$ system: experiments and simulations. European Journal of Mineralogy 13, $509 \quad 453-466$.

510 Baker, L.L., Rutherford, M.J., 1996. The effect of dissolved water on the oxidation state

511 of silicic melts. Geochimica et Cosmochimica Acta, 60, 2179-2187.

512 Berry, A. J., O'Neill, H. S., Jayasuriya, K. D., Campbell, S. J. and Foran, G. J. (2003a).

$513 \quad$ "XANES calibrations for the oxidation state of iron in a silicate glass." American $514 \quad$ Mineralogist 88(7): 967-977.

515 Botcharnikov, R.E., Koepke, J., Holtz, F., McCammon, C., Wilke, M., 2005. The effect

516 of water activity on the oxidation and structural state of Fe in a ferro-basaltic melt.

517 Geochimica Cosmochimica Acta, 69, 5071-5085.

518 Burgisser, A., Scaillet, B., 2007. Redox evolution of a degassing magma rising to the 
surface. Nature 445, 194-197, doi 10.1038/nature05509.

520 Candela, P.P., 1986. The evolution of aqueous vapor from silicate melts: Effect on

521 oxygen fugacity. Geochimica Cosmochimica Acta 50, 1205-1211.

522 Carmichael, I.S.E., 1991. The redox states of basic and silicic magmas: a reflection of

523 their source regions $\mu$ Contributions to Mineralogy and Petrology 106, 129-141.

524 Castro, J.M., Beck, P., Tuffen, H., Nichols, A.R.L., Martin, M., 2008. Timescales of

525 spherulite crystallization in obsidian inferred from water concentration profiles.

526 American Mineralogist 93, 1816-1822.

527 Colony, R., Howard, A.D., 1934. Observations on spherulites. American Mineralogist $52819,515-524$.

529 Cottrell, E., Kelley, K. A., Lanzirotti, A.T., Fischer, R. (submitted to Chemical

530 Geology). High-Precision Determination of Iron Oxidation State in Silicate

531 Glasses Using XANES.

532 Delaney, J. S., Dyar, M. D., Sutton, S. R., Bajt, S., 1998. Redox ratios with relevant

533 resolution: Solving an old problem by using the synchrotron microXANES probe.

534 Geology 26, 139-142.

535 Donald, S.B., Swink, A.M., Schreiber, H.D., 2006. High-iron ferric glass. Journal of

536 Non-crystalline Solids 352, 539-543.

537 Gaillard, F., Scalliet, B., Pichavant, M., Beny, J-M., 2001. The effect of water and $f \mathrm{O}_{2}$ on

538 the ferric-ferrous ratio of silicic melts. Chemical Geology 174, 255-273.

539 Gaillard, F., Scalliet, B., Pichavant, M., 2002. Kinetics of iron oxidation-reduction in

540 hydrous silicic melts. American Mineralogist 87, 829-837.

541 Gaillard, F., Schmidt, B., Mackwell, S., McCammon, C., 2003a. Rate of hydrogen-iron 
542 redox exchange in silicate melts and glasses. Geochimica et Cosmochimica Acta 67,

$543 \quad 2427-2441$.

544 Gaillard, F., Pichavant, M., Scaillet, B., 2003b. Experimental determination of activities

545 of $\mathrm{FeO}$ and $\mathrm{Fe}_{2} \mathrm{O}_{3}$ components in hydrous silicic melts under oxidizing conditions.

546 Geochimica et Cosmochimica Acta 67, 4389-4409.

547 Gaillard, F., Pichavant, M., Mackwell, S., Champallier, R., Scaillet, B., McCammon, C.,

548 2003c. Chemical transfer during redox exchanges between $\mathrm{H}_{2}$ and Fe-bearing silicate

549 melts. American Mineralogist 88, 308-315.

550 Geschwind, C.H., Rutherford, M.J., 1995. Crystallization of microlites during magma

551 ascent: the fluid mechanics of 1980-1986 eruptions at Mount St. Helens. Bulletin of

552 Volcanology 57, 356-370.

553 Hess, K.U., Dingwell, D.B., 1996. Viscosities of hydrous leucogranitic melts: A non-

554 Arrhenian model. American Mineralogist 81, 1297-1300.

555 Hildreth, W., Christiansen, R.L., O’Neil, J.R., 1984. Catastrophic isotopic modification

556 of rhyolitic magma at times of caldera subsidence, Yellowstone Plateau volcanic field.

557 Journal of Geophysical Research 89, 8339-8369.

558 Kress, V., Carmichael, I.S.E., 1991. The compressibility of silicate liquids containing

$559 \mathrm{Fe}_{2} \mathrm{O}_{3}$ and the effect of composition, temperature, oxygen fugacity and pressure on their

560 redox states. Contributions to Mineralogy and Petrology 108, 82-92.

561 Manley, C. R., 1992. Extended cooling and viscous flow of large, hot rhyolite lavas:

562 implications of numerical modeling results. Journal of Volcanology and Geothermal

563 Research 53, 27-46.

564 Manley, C.R., Fink, J.H., 1987. Internal textures of rhyolite flows as revealed by 
565 research drilling. Geology 15, 549-552.

566 Mathez, E.A., 1984. Influence of degassing on oxidation states of basaltic magmas.

567 Nature 310, 371-374.

568 Métrich, N., Susini, J., Foy, E., Farges, F. Massare, D., Sylla, L., Lequien, S., Bonnin-

569 Mosbah, M., 2006. Redox state of iron in peralkaline rhyolitic glass/melt: X-ray

570 absorption micro-spectroscopy experiments at high temperature. Chemical Geology

$571 \quad 231,350-363$.

572 Moore, G., Righter, K., Carmichael, I.S.E., 1995. The effect of dissolved water on the

573 oxidation state of iron in natural silicate liquids. Contributions to Mineralogy and

574 Petrology 120, 170-179.

575 Moriizumi, M., Nakashima, S., Okumura, S., Yamanoi, Y., 2008. Color-change processes

576 of a plinian pumice and experimental constraints on color-change kinetics in air of an

577 obsidian. Bulletin of Volcanology DOI 10.1007/s00445-0080202-5.

578 Mueller, R.F., 1971. Oxidative capacity of magmatic components. American Journal of

579 Science 270, 236-243.

580 Newman, S., Stolper, E.M., Epstein, S., 1986. Measurement of water in rhyolitic glasses:

581 Calibration of an infrared spectroscopic technique. American Mineralogist 71, 1527-

5821541.

583 Northrup, Jr., C.J.M., Gerlach, T.M., Modreski, P.J., Galt, J.K., 1977. Potential fuel

584 production from magma. Sandia National Laboratories Report SAND77-0509, 1-34.

585 Peck, L.C., 1964. Systematic analysis of silicates: U.S.G.S. Bulletin 1170, 80.

586 Sato, M., Wright, T.L., 1966. Oxygen fugacities directly measured in magmatic gases.

587 Science 153, 1103-1105. 
588 Sato, M. 1978. Oxygen fugacity of basaltic magmas and the role of gas-forming

589 elements. Geophysical Research Letters 5, 447-449.

590 Sisson, T.W. and Grove T.L. 1993. Experimental investigations of the role of $\mathrm{H}_{2} \mathrm{O}$ in

591 calc-alkaline differentiation and subduction zone magmatism. Contributions to

592 Mineralogy and Petrology, 113, 143-166.

593 Smith, R.K., Tremallo, R.L., Lofgren, G.E., 2001. Growth of megaspherulites in a

594 rhyolitic vitrophyre. American Mineralogist 86, 589-600.

595 Stasiuk, M.V., Barclay, J., Carroll, M.R., Jaupart, C., Ratte, J.C., Sparks, R.S.J., Tait,

596 S.R., 1993. Degassing during magma ascent in the Mule Creek vent (USA). Bulletin of

597 Volcanology 58, 117-130.

598 Stevenson, R.J., Briggs, R.M., Hodder, A.P.W., 1994. Physical volcanology and

599 emplacement history of the Ben Lomond rhyolite lava flow, Taupo Volcanic Centre, New

600 Zealand. New Zealand Journal of Geology and Geophysics 37, 345-358.

601 Stolper, E.S., 1982. The speciation of water in silicate melts. Geochimica et

602 Cosmochimica Acta 46, 2609-2620.

603 Swanson, S.E., Naney, M.T., Westrich, H.R., Eichelberger, J.C., 1989. Crystallization

604 history of Obsidian Dome, Inyo Domes, California. Bulletin of Volcanology 51, 161-

605176.

606 Tuffen, H., Castro, J.M., 2009. The emplacement of an obsidian dyke through thin ice:

607 Hrafntinnuhryggur, Krafla, Iceland. Journal of Volcanology and Geothermal Research.

608 doi:10.1016/j.jvolgeores.2008.10.021.

609 Tuffen, H., Castro, J.M., Wilson, L., in Review. The thermal effects of spherulite

610 crystallization in rhyolitic lava. Earth and Planetary Science Letters. 
611 Watkins, J., Magma, M., Huber, C., and Martin, M., 2009. Diffusion-controlled

612 spherulite growth in obsidian inferred from $\mathrm{H} 2 \mathrm{O}$ concentration profiles. Contributions to

613 Mineralogy and Petrology 157, 163-172.

614 Westrich, H.R., Stockman, H.W., Eichelberger, J.C., 1988. Degassing of rhyolitic

615 magma during ascent and emplacement. Journal of Geophysical Research 93, 6503-

6166511.

617 Wilke, M., G. M. Partzsch, R. Bernhardt, Lattard, D., 2005. Determination of the iron

618 oxidation state in basaltic glasses using XANES at the K-edge. Chemical Geology 220,

$619 \quad 143-161$.

620 Wright, F.E., 1915. Obsidian from Hrafntinnuhryggur, Iceland: Its lithophysae and

621 surface markings. Bulletin of the Geological Society of America 26, 255-286.

622 Zhang, Y., Stolper, E.M., Wasserburg, G.J., 1991. Diffusion of water in rhyolitic glasses.

623 Geochimica et Cosmochimica Acta 55, 441-456.

624

625

626

627

628

629

630

631

632

633

634

635

636

637

638

639

640

641

642

643

\section{Figure Captions}

Figure 1. A) Photomicrograph of spherulites (round and elliptical, black) in obsidian (brown). Various analytical points and traverses are shown (emp=electron probe microanalyzer; FTIR=Fourier Transform Infrared Spectroscopy; XANES=x-ray absorption near-edge spectroscopy). Black diamonds indicate approximate locations of $\mu$-XANES measurements. Broader dark swaths are tracks left by a laser ablation ICPMS (these data are not discussed here). B) A back-scattered electron image showing typical internal spherulite texture. Bright phases are clinopyroxene and magnetite. C) An $\mathrm{OH}^{-}$ concentration profile determined by FTIR collected along the lower right traverse in frame A. The vertical grey line is the approximate location of the colorless-brown glass boundary.

Figure 2. Major element compositions of glass leading up to a spherulite margin (at position $=0 \mu \mathrm{m}$ ). All analyses were collected with an electron probe microanalyzer. The vertical grey bars demarcate the approximate $( \pm 10 \mu \mathrm{m})$ position of the colorless-brown glass boundary.

Figure 3. Raw $\mu$-XANES spectra of the pre-edge region, model components, and model 
644 fits for two points within the glassy matrix depicted in Figure 1A (a) Point 1 inside the 645 colorless glass halo and (b) point 2 in the distal brown glass. (c) Model fits of the spectra 646 in (a) and (b) baseline-subtracted and superimposed. Approximate positions of analysis points are shown on the inset photomicrograph. These data show the relative changes in ratio of $\mathrm{Fe}^{2+}$ to $\mathrm{Fe}^{3+}$ in the colorless and brown matrix glass. Iron in the glass near the

649 spherulite (point 1) is significantly reduced compared to that in the far-field brown glass 650 (point 2).

Figure 4. Colorless-glass rim width versus the apparent spherulite radius, measured on photomicrographs of the Krafla obsidian (solid dots). Error in rim width, shown as vertical bars, ranges from about $10-20 \%$, and originates from the diffuse nature of the colorless-brown glass boundaries. Regression curve is a power law function of the form: $\mathrm{y}=2 \mathrm{x}^{0.69} ; \mathrm{R}^{2}=0.97$. Solid triangles are the predicted rim widths based on the experimentally constrained hydrogen-iron reaction rate constant of Gaillard et al. (2003b), and the assumption that the rims developed during the interval of time that the spherulites grew, which in turn, is taken from the growth rate data of Castro et al. (2008).

Figure 5. Photomicrographs (500X; $200 \mu \mathrm{m}$ f.o.v.) collected on: A) a natural spheruliteglass combination, and B-D) an experimentally heated spherulitic obsidian. Frame A) shows the natural appearance of the spherulite margin (at top) and colorless and brown glass as viewed in transmitted, plane polarized light. The wafer is $197 \mu \mathrm{m}$ thick. Frame B) shows the typical appearance of the spherulite and colorless and brown glass after heating a similar piece of obsidian to $770 \mu \mathrm{C}$ for approximately 90 minutes. This wafer is about $202 \mu \mathrm{m}$ thick. Note the thin veneer $(\sim 10 \mu \mathrm{m})$ of plagioclase coating the spherulite margin (upper right) and the relative brightening of the colorless glass halo. Note also the crack running roughly in the center of the colorless halo with a string of small vesicles on its tip. Frame C) shows another view of the incipient crystallization and vesiculation that occurred during heat treatment. The vesicles here formed along an arcuate fracture in the colorless glass zone. Frame D) is a backscattered electron image of the three zones developed at the spherulite margin: the brown microlite rich fringe (a), plagioclase veneer (b), and the colorless and Fe-reduced matrix glass (c).

Figure 6. An $\mathrm{OH}^{-}$concentration profile measured along a traverse extending from a spherulite in the heated obsidian sample. The position of traverse is shown on the subjacent photomicrograph. The vertical dashed and solid grey lines on the profile bound the light brown glass zone that may have formed as a result of degassing of hydrogen into the crack shown in the photomicrograph. Note the coincidence between the depression in the $\mathrm{OH}^{-}$concentration profile and the position of the crack at $\sim 75-80 \mu \mathrm{m}$. 